\title{
JOHN DEWEY: RECONSTRUIR O VALOR DO SOCIAL. UMA CHAMADA DA DEMOCRACIA À EDUCAÇÃO
}

\author{
María Alejandra Olivera ${ }^{1}$ \\ (D)https://orcid.org/0000-0003-4997-7624 \\ Leoni Maria Padilha Henning ${ }^{2}$ \\ (Dhttps://orcid.org/0000-0001-8004-2371
}

Resumo: John Dewey é uma referência teórica importante quando falamos de democracia e educação. Para poder vislumbrar o escopo que suas ideias têm hoje é um objetivo viável e, talvez, necessário diante da crise de valor social gerada pelas atuais forças neoliberais. Recuperar o sentido de um ideal que não busca uma imposição dogmática, mas é pensado como um fim orientado por um modelo crítico e normativo, que permite avaliar as deficiências e problemas das democracias reais; e, ao mesmo tempo, orientar e dirigir as ações necessárias para a reconstrução de cada instância da vida democrática, é um incentivo importante para se comprometer com o que Dewey chamou de responsabilidade para realizarmos novamente a democracia. Nesse contexto, por que falamos sobre o chamado da democracia à educação? É nesse sentido que tentaremos avançar no presente artigo que foi construído a partir de uma investigação bibliográfica.

Palavras-chave: John Dewey. Democracia. Educação. Filosofia.

1 Professora adjunta nas cátedras da área filosófico-pedagógica do Departamento de Educação na Facultade de Ciências Humanas da Universidade Nacional do Centro da Província de Buenos Aires (UNCPBA), onde desenvolve também atividades e projetos de pesquisa. Atualmente, cursa o Doutorado em Educação na mesma instituição. E-mail: oliveramariaalejandra@gmail.com

2 Doutora em Educação e pesquisadora na área de Filosofia da Educação, atualmente, vinculada ao Programa de Pós-graduação da Universidade Estadual de Londrina como professora sênior. E-mail: leoni.henning@yahoo.com 


\section{JOHN DEWEY: RECONSTRUCT THE VALUE OF THE SOCIAL. A CALL FROM DEMOCRACY TO EDUCATION}

Abstract: John Dewey is a leading theoretical reference when we talk about democracy and education. Being able to glimpse the scope that his ideas have today is a viable task and, perhaps, a necessary purpose in the face of the social value crisis generated by current neoliberal forces. To recover the sense of an ideal that does not seek a dogmatic imposition, but is thought as an end oriented by a critical and normative model, which allows us to assess the deficiencies and problems of the real democracies; and, at the same time, to guide and to direct the necessary actions for the reconstruction of each instance of democratic life, is an important incentive if we commit to what Dewey called the responsibility of accomplishing democracy again. In this context, why do we talk about the call for a democratic to education? In this sense, we will move forward in this article which was built from a bibliographic investigation.

Keywords: John Dewey. Democracy. Education. Philosophy.

\section{JOHN DEWEY: RECONSTRUIR EL VALOR DE LO SOCIAL. UN LLAMADO DE LA DEMOCRACIA A LA EDUCACIÓN}

Resumen: John Dewey es un referente teórico destacado cuando hablamos de democracia y educación, poder vislumbrar el alcance que hoy tienen sus ideas es un propósito viable y, quizás, necesario frente a la crisis de valor de lo social que generan las fuerzas neoliberales actuales. Recuperar el sentido de un ideal que no busca una imposición dogmática, sino que se piensa como un fin orientado por un modelo crítico y normativo, que permite evaluar las deficiencias y los problemas de las democracias reales; $y$, al mismo tiempo, orientar y guiar las acciones necesarias para la reconstrucción de cada instancia de la vida democrática, es un importante aliciente para comprometerse con aquello que Dewey llamaba la responsabilidad de realizar de nuevo la democracia. En este contexto, ¿por qué hablamos del llamado de la democracia a la educación? En este sentido vamos a procurar avanzar en este artículo que fue construido a partir de una investigación bibliográfica.

Palabras clave: John Dewey. Democracia. Educación. Filosofía. 


\section{Introducción}

Este texto tiene como propósito destacar el alcance actual del ideal democrático, presente en el pensamiento filosófico-pedagógico de John Dewey, para comprender los desafíos que tienen por delante las democracias actuales y sus respectivas propuestas educativas. La posibilidad de abordar con mayor profundidad esta problemática se sustenta en el trabajo de investigación realizado para obtener el título de Magister en Educación, por la Universidad Nacional del Centro de la Provincia de Buenos Aires Argentina, en el año 2018, orientado por la Dra. Leoni Maria Padilha Henning; allí llevamos a cabo un recorrido conceptual por los temas centrales de la perspectiva deweyniana, y analizamos, en función de delimitar nuestra referencia teórica, los planteos que atañen al vínculo entre democracia y educación; además de otras cuestiones que no son objeto de este escrito.

La relación entre democracia y educación es planteada, por Dewey, como un ideal crítico y normativo indispensable para reflexionar sobre los significados de la democracia en tiempos de crisis; donde se encuentra desvalorizada, sometida a imperativos económicos y de poderes autoritarios, que agobian sus principios de una vida más justa, y compartida con el afán de transformación y emancipación humana y social.

Para Dewey la democracia es un proceso vital, social y cooperativo que necesita garantías de una asociación consciente, inteligente y reflexiva. Por ello, desarrolló toda su obra a la luz de este nexo fundamental, con el fin de avanzar frente a la complejidad de los cambios presentes y futuros que tiene por delante las sociedades democráticas.

Articularemos este texto en el interrogante sobre el valor de lo social para, primero, colocar el concepto de democracia de Dewey; avanzar luego sobre la tarea que define para la filosofía, para poder analizar de forma breve, cuál es el beneficio que esto conlleva a la democracia como una forma de vida compartida. Luego, en tercer lugar, delinearemos la tarea de la educación vinculada a ese valor social que necesita construirse desde los parámetros de una inteligencia común. Y finalmente, abordaremos a la conclusión para integre los puntos anteriores, al determinar cuál es la importancia de los puntos claves que Dewey coloca para continuar la reflexión; ante la necesidad de superar lógicas instrumentales y dogmáticas, que neutralizan las nociones de lo social y de lo público. 
Indagar en esta dirección, desde el ámbito propio de lo pedagógico, implicará repensar el papel de la educación ante la demanda de asumirse como colaboradora sustancial en la reconstrucción de la democracia. Y nos permitirá señalar por qué la reconstrucción de la democracia y de la educación es una tarea siempre en curso.

\section{Una concepción de democracia}

John Dewey dio fuerza a la idea de que "[...] el cometido de la democracia es y será siempre la creación de una experiencia más libre y más humana, en la que todos participemos y a la que todos contribuyamos." (DEWEY, 1996, p. 205). Con esta idea normativa el autor definió un propósito, indispensable para pensar nuestro presente; que vincula a la democracia con la práctica de una experiencia colectiva sustancialmente viva, contextualizada, situada, que requiere de una tarea común, reflexiva, sensible a las problemáticas reales de cada sociedad; y movilizada por un principio de emancipación y transformación social.

Las posibilidades de este ideal democrático, que formuló Dewey, no puede realizarse sin una finalidad y un recorrido pedagógico y formativo, que procure el desenvolvimiento y la práctica colectiva (cooperativa) de un pensamiento crítico y un hacer, movidos por el compromiso social que implica el valor dado a la participación democrática. Condición sin la cual no podríamos reconocernos como parte de una experiencia común en la que estamos inmersos desde que nacemos en sociedad.

La propuesta de Dewey se articula en el propósito de reconstruir el vínculo entre democracia y educación, desde un abordaje crítico que cuestiona cualquier planteo instrumental, con interés utilitario en base a un ideal fijo, que se presenta como modelo a implementarse. Para nuestro autor, la democracia es un proceso vivo y vital que requiere de una reconstrucción constante; vista como una forma ética de vida que no puede permanecer reducida a un estándar inmutable, y menos aún quedar atrapada por una lógica de reproducción social acrítica o autoritaria y deshumanizante.

Dewey piensa a la democracia y a la educación en un nexo inseparable de cooperación, de comunidad, de necesidad mutua, regido por un ideal práctico; que se distingue por un intento, ético y político, de integrar conocimientos, valores y fines, 
mediados por la indagación y la reflexión para avanzar en la conformación de sociedades cada vez más emancipadas y democráticas.

Somos testigos de que persisten, en la actualidad, planteos políticos y educativos que imponen conocimientos estandarizados acordes con dogmatismos, interés y metas económicas y políticas contrarias al beneficio público; y, también, vemos como estas posturas bloquean procesos de emancipación, puesto que permanecen ajenas y separadas de intereses comunes y democráticos; para los que se requiere comprender el mundo en su complejidad, sus conflictos, sus males, las necesidades y, también, las posibilidades reales capaces de alcanzar formas de vida más justas e igualitarias. Frente a esta coyuntura podemos preguntarnos: ¿Qué valor tiene hoy el ideal democrático que plantea John Dewey? ¿Qué desafíos supone para la educación actual? ¿Qué tipo de vínculos existen entre la democracia y la educación de nuestro tiempo? ¿Cómo respondemos hoy a la necesidad de reconstruir esta relación?

Dewey puede orientarnos si nos apoyamos en su teoría filosófica, política y pedagógica que atenta a los avatares y problemas reales de la vida humana; atentos a que su propósito va más allá de hacer una mera descripción de la situación, o de lograr una representación absoluta y categórica de lo que acontece en la realidad. Su objetivo fue comprender lo que pasa a partir de determinar las consecuencias concretas de las ideas que dan forma a la vida real, concentrándose en la democracia, como uno de los problemas contemporáneos más acuciantes.

Es por esto que la visión deweyniana de democracia es la base central para abordar todos los demás temas que interesaron al autor. Sin embargo, al acercarnos a su teoría debemos considerar que su intensión no es plantear una nueva concepción de democracia, como un modelo más eficaz y perfeccionado; al contrario, es impulsar una actitud crítica que nos permita asumir el desafío de vislumbrar la dimensión de la tarea de poner a la humanidad sobre el camino democrático, como solía decir.

Para comprender, de forma fehaciente, lo que representa este ideal democrático es necesario referirse primero a lo que el autor entiende por ideal. Afirmaba, en sus textos, que es pura ilusión sostener ideales con fines remotos e inmutables como única posibilidad para dar solución a los problemas actuales; por esa razón, persistentemente, se alejó de todo ideal abstracto e inamovible. Para el autor un ideal debe ser siempre 
precedido por una realidad concreta, y como ya señalamos, no estar relacionado con un logro lejano y aislado del presente; porque su función es generar un planteo más amplio y complejo del bien que se establece a partir de lo que vivimos.

De esta manera el ideal queda definido como un fin, que puede realizarse en la medida que es visto como una sucesión de medios y fines renovados, que permita ir acercándose a lo que se considera deseable o mejor; de forma continua y planificada. Por ello, el ideal democrático deweyniano se convierte en un modelo crítico y normativo para evaluar las deficiencias y los problemas de las democracias reales; $y$, de tal modo, orientar y guiar las acciones necesarias para la reconstrucción ${ }^{3}$ de cada instancia de la vida democrática. Ya que, como piensa el autor, la democracia se rehace en el día a día, en las interacciones sociales y en todas las instituciones que la representan.

Sin embargo, la reconstrucción no es una tarea fácil ni se da de forma automática, sino que implica problematizar los conflictos en el interior de las propias instituciones democráticas y en las actitudes de cada ser humano que la constituye. Por esto, la reconstrucción de la democracia requiere seguir métodos democráticos que se establecen únicamente, como afirma el autor, "[...] con todos los recursos proporcionados por la inteligencia colectiva operando en acción cooperativa" (DEWEY, 1946, p. 166).

Es la cooperación social el eje que vertebra la posibilidad real de alcanzar una vida más democrática, porque exige una percepción plena de las consecuencias de la actividad conjunta y de la participación distintiva de cada sujeto, para alcanzar este propósito común. Pero, cabe destacar, que Dewey no pensaba en el método como una fórmula que determina los pasos para lograr cierto objetivo; al contrario, el método que contribuya a la reconstrucción democrática debe ser experimental, en el sentido que demanda una observación constante y una revisión crítica y flexible de las consecuencias que se producen en situaciones concretas de la vida social. Esta acción sistemática y orgánica a los fines democráticos, en efecto, es la que nos permitirá mejorarla.

\footnotetext{
${ }^{3}$ En términos generales la reconstrucción, en la perspectiva deweyniana, implica llevar a cabo un proceso de investigación o indagación crítica sobre prejuicios, tradiciones, costumbres e ideas de carácter dogmático; esto es, que se presentan como definitivas, inmutables y universales. Y al mismo tiempo, este análisis crítico debe posibilitar un diagnóstico inteligente que permita la proyección de fines y métodos acorde con realidades humanas y sociales concretas.
} 
Como ya señalamos, en la teoría deweyniana los temas centrales se nuclean alrededor de la noción de democracia como forma de vida orientada a la cooperación humana. John Dewey sostiene que esta cooperación debe ser promovida por un determinado contexto de asociación, ya que considera que los rasgos sociales vigentes son los que orientan las conductas individuales y sociales ${ }^{4}$. Es por ello que, la democracia requiere ser reconstruida por todos los sujetos que conforman la sociedad y no puede sostenerse automáticamente, o sólo garantizarse en el cumplimiento de las prescripciones formuladas por una reglamentación estática y predefinida.

En el marco de este planteo, una de las primeras preocupaciones de Dewey fue acentuar que la interacción y la comunicación social son las mejores condiciones de posibilidad para una sociedad constituida democráticamente. Por esa razón, define a la democracia como "[...] un modo de vivir asociado, de experiencia comunicada juntamente" (DEWEY, 1995, p. 82). Cuyas características principales son, por un lado, intereses compartidos que se constituyan en factor de control social, para orientar planes y prácticas más democráticas; y, por otro, una mayor cooperación entre los grupos sociales a partir de una mejora constante en los hábitos sociales de comunicación; que serán modificados acorde a las nuevas situaciones que provoca un contexto de intercambio amplio y plural.

El desarrollo de una vida social con estas características impulsa a que cada individuo refiera su propia acción a la de los demás, en un sentido que no es de asimilación o imitación; sino que busca, efectivamente, un alto grado de integración social. Donde se valorice la diversidad como fuente de enriquecimiento de la vida social y se amplíen las perspectivas para lograr una significación más plena de los pensamientos y acciones compartidas, en cada circunstancia.

\footnotetext{
${ }^{4}$ Para Dewey es central la relación que existe entre la cultura y la naturaleza humana ya que "[...] todo conocimiento, juicio y creencia, representa un resultado adquirido, por la acción de los impulsos naturales en relación con el medio." (DEWEY, 1930, p. 30) Pero esta colocación no es en términos absolutos, sino que requiere ser entendido críticamente para comprender la complejidad que encierra la vida en democracia y las interacciones humanas. Esta postura señala que no todos los rasgos sociales son beneficiosos para asegurar las condiciones necesarias de desarrollo de las capacidades de la naturaleza humana. En definitiva, afirma, que "[...] los acontecimientos sociales continuarán siendo productos de la interacción de la naturaleza humana con las condiciones culturales. Por tanto, la cuestión primordial y fundamental será siempre precisar qué clase de resultados sociales queremos en forma suprema." (DEWEY, 1946, p. 162).
} 
El autor define, en lo dicho anteriormente, su posicionamiento político y social (respecto a lo que significa vivir en democracia) desde un análisis profundo sobre los fallos y las limitaciones de la democracia de su época. Dewey plantea la necesidad de una democracia radical que supere los problemas del liberalismo clásico: especialmente el individualismo a ultranza determinado por las propias leyes del mundo económico, comprendido como un mundo aséptico e imparcial ${ }^{5}$. Que trae como consecuencia la escasez de contenido social, justamente, como producto de la falta de control político sobre el accionar económico.

\section{La tarea de la filosofía para la democracia}

El significado que tiene la democracia en este contexto teórico, también, está fundamentada por un claro posicionamiento filosófico, que destaca la importancia de la interacción humana entendida como una intervención activa y cooperativa sobre el ambiente, para dar valor a todos los aspectos de la vida compartida; y, a partir de allí, poder establecer normas legitimadas que orienten cada una de las acciones del grupo social.

Esta concepción filosófica tiene una intensión práctica concreta, centrada en un problema que para Dewey es inequívocamente humano: el de cómo vivir en un contexto social que considere central el libre intercambio de experiencias vitales, donde se garantice la reciprocidad de intereses y la intercomunicación social; con la finalidad de mejorar las condiciones de vida democrática para alcanzar un verdadero bienestar social y moral del hombre.

Este anhelo es el principal objetivo de la filosofía de Dewey, y por ello la presenta como una crítica fuerte a las ideas y consecuencias de cualquier filosofía que se caracterice como conocedora de la realidad última, inmutable y; a la vez, garante de un

\footnotetext{
${ }^{5}$ Este modelo se conoce como Liberalismo clásico o del laissez-faire, cuya característica central es el impulso de la libre actividad económica ejercida por individuos que buscan su propio lucro personal. Así, La libertad individual es vista como un derecho natural independiente de cualquier forma de relación social o política; y por ello, era necesario el distanciamiento de cualquier acción política que pueda interferir en este libre ejercicio individual y económico.
} 
conocimiento verdadero y unificador ${ }^{6}$. En varios de los textos, en los que hace referencia a su fundamentación filosófica, desarrolla ampliamente la crítica que señalamos; especialmente en, dos de sus obras claves al respecto, La reconstrucción de la filosofía (1959) publicado por primera vez en 1920, y El Hombre y sus problemas (1952) publicado originalmente en 1946.

No vamos a profundizar tal desarrollo, en este trabajo, porque excede su objetivo particular que lo origina; pero podemos destacar el punto principal, que para Dewey representa la verdadera actuación de la filosofía: su tarea fundamental es impulsar una acción crítica sobre los problemas que son, por sí mismos, vitalmente actuales. Esto da un lugar central a la investigación filosófica, en la medida que es capaz de orientarse hacia una discusión inteligente de todas las cuestiones que obran en la vida humana.

Esta tarea crítica debe ser entendida como una búsqueda, por medio de una acción reflexiva permanente, para comprender las dificultades que impiden el progreso humano en términos de mayor justicia y libertad; con el fin de promover nuevos métodos y hábitos que impulsen acciones colectivas, para superar concepciones y prácticas que continúan con los planteos dogmáticos y el aislamiento o desvinculación de los reales asuntos sociales.

Es necesario hacer una aclaración sobre el rol que debe cumplir la filosofía según Dewey, en sus palabras: "A la filosofía no le es factible, por sí sola, resolver los conflictos y despejar las confusiones del mundo de hoy. Sólo los miembros asociados del mundo pueden realizar esta obra en una acción cooperativa". (DEWEY, 1952, p. 20) Este es el significado de la filosofía que buscamos destacar en función del desafío de pensar la tarea de educación frente al ideal democrático; ya que, animar esta actitud filosófica puede representar un cambio sustancial en los procesos de formación de sujetos comprometidos con la transformación de sus propios contextos sociales.

\footnotetext{
${ }^{6}$ Toda filosofía que pretenda reducir la realidad a un patrón único de verdad favorece, también, una idea de conocimiento completo en sí mismo, al que nada le falta y no experimenta ningún cambio sustancial. En su planteo critico sobre la influencia de este tipo de filosofía, y sus diversas formas, Dewey señala: "Fue legada a generaciones de pensadores como axioma indiscutible la idea de que el conocer es intrínsecamente una mera percepción o visión de la realidad, es decir, el concepto de conocimiento como espectáculo. Tan profundamente tomó contextura esta idea que dominó durante siglos, incluso cuando ya el progreso real de la ciencia había demostrado que el conocimiento es el poder de transformar el mundo, y siglos después de que la práctica del conocimiento eficaz había adoptado el método experimental". (DEWEY, 1959, p. 178).
} 
Para que esto sea posible la filosofía debe abordar la realidad como una cuestión de diversidad, de cambio, de conflicto y de lucha; lo que la lleva a definirse por su cualidad práctica y a convertirse en operante y experimental, como señala Dewey. Lo que se plantea es una transformación de la naturaleza de la filosofía, cuya consecuencia debe ser invertir la idea de lo real, como algo consumado y definitivo, por otra idea de lo real: como posibilidad permanente, donde será necesario descubrir los obstáculos que impiden el logro de aquello que se configura como interés y deseo colectivo.

Esta visión de la tarea de la filosofía propone pasar de un ideal prefijado y alejado de los acontecimientos humanos a un nuevo ideal, con verdaderas posibilidades de mejorar la realidad. Dice Dewey:

Este cambio no significa un rebajamiento de la filosofía en dignidad, desde un plano elevado a otro de burdo utilitarismo. Significa que la función primordial de la filosofía es la de racionalizar las posibilidades de la experiencia, y de un modo especial las de la experiencia humana colectiva (DEWEY, 1959, p. 188).

A partir de esta posición filosófica es que Dewey sostiene que la democracia requiere de una constante consideración y crítica de la calidad de sus ideas y acciones, porque el valor de una democracia está directamente asociado al tipo de ideas que la fundamenta y que determina el rumbo de sus políticas. En esto consiste la reconstrucción de la democracia a la que nos referimos anteriormente.

\section{La tarea de la educación: experiencias educativas}

En esa misma línea que venimos desarrollando, Dewey piensa que la educación puede cumplir un papel importante frente a esta necesidad de crítica y análisis reflexivo, en la medida que colabore con el desarrollo de la capacidad de, lo que llama, discriminar bajo la superficie; o sea, ser capaces de una conducta inteligente y poco ingenua frente a la realidad y los procesos de manipulación o de inocencia artificial y adquirida, que la misma educación genera cuando aísla a los alumnos de los problemas sociales y los males políticos y económicos reales. 
Este posicionamiento pedagógico define a la educación como "[...] una constante reorganización o reconstrucción de la experiencia" (DEWEY, 1995, p. 73), que además de dar sentido a dicha experiencia también aumenta las capacidades para dirigir otras nuevas. Estos dos aspectos que destacan: la importancia de encontrar conexiones y continuidades en las actividades que se realizan para descubrir el sentido de lo que se hace, y la posibilidad de dirigir y controlar las próximas acciones para generar consecuencias beneficiosas; representan, según Dewey, una experiencia auténticamente educativa.

La educación planteada de este modo está íntimamente vinculada a una democracia que requiere vivir de forma democrática; pero vivir de esta forma no es ajustarse a una serie de reglas fijas, que establecen como hacerlo; sino, es la oportunidad de actuar en un espacio donde se puedan desarrollar hábitos flexibles y en constante crecimiento. Así será posible: discernir las complejidades de las situaciones que vivimos y nos afectan; proponer hipótesis o alternativas para explicar los acontecimientos y las ideas; poder aprender de la experiencia compartida en un contexto de formación planificada; evaluar con criterios de objetividad y justicia los valores y opiniones que se encuentren en conflicto; y ser capaces de cambiar las propias perspectivas sobre las consecuencias de nuestras acciones y su relación con las de los demás.

Lo realmente significativo de la visión pedagógica de Dewey es que quiere superar el modelo de formación de capacidades o disposiciones individuales, entendido como preparación para el futuro y garantía de progreso; su planteo implica un abordaje comprometido con el presente y situado en el espacio de las múltiples relaciones sociales y culturales. Su interés es revalorizar el rol de las instituciones, que tienen injerencia en la formación humana, para promover el crecimiento intelectual y emocional en el marco de la vida compartida de una comunidad.

Dewey busca con este planteo resaltar la importancia de la tarea cotidiana de una educación pública y sistemática, con claridad en sus metas, orientada a brindar a cada alumno la posibilidad de poder significar toda experiencia desde un pensamiento inteligente y de carácter social. Lo central aquí es que no se trata de educar una facultad o competencia, sino de estimular la formación, como dice Richard Bernstein, de: 
[...] un conjunto de disposiciones que implican imaginación, sensibilidad ante la complejidad de las situaciones concretas, consciencia de sus consecuencias, capacidad de escuchar y aprender de las opiniones de otros, así como un actitud experimental falibilista a la hora de intentar resolver problemas (BERNSTEIN, 2010, p. 260).

Lo central es que estas disposiciones tienen que desenvolverse mediante actividades e interacciones referidas a cuestiones de la propia vida social. No se logran de forma definitiva como resultado de acciones educativas prefijadas y uniformes; su desenvolvimiento es progresivo y se vincula a la posibilidad concreta de ponerlas en práctica, por medio de una actividad en la que participamos con otros sujetos.

El sentido de lo social es notoriamente decisivo en esta propuesta y remite a la idea de comunicación. Es por medio de esta última que se logran ampliar las significaciones que nos permiten vivir en cada época y, además, participar para realzar, ahondar y consolidar estas significaciones de forma compartida. Pero, Dewey advierte que la comunicación no es sólo un medio para poder alcanzar valores y fines comunes, es además el sentimiento de comunidad, de comunión, realizado; es solidaridad.

En Democracia y Educación (1995), publicado originalmente en el año 1916, uno de los textos indispensables para comprender su idea de educación y la función social que esta tiene, expresa con claridad:

La sociedad no sólo continúa existiendo por la transmisión, por la comunicación, sino que puede decirse muy bien que existe en la transmisión y en la comunicación. Hay más que un vínculo verbal entre las palabras común, comunidad y comunicación. Los hombres viven en una comunidad por virtud de las cosas que tienen en común; y la comunicación es el modo en que llegan a poseer cosas en común. Lo que han de poseer en común con el fin de formar una comunidad o sociedad son objetivos, creencias, aspiraciones, conocimientos; una inteligencia común [...] Tales cosas no pueden pasarse físicamente de unos a otros, como ladrillos; no pueden compartirse como varias personas comparten un pastel dividiéndolo en trozos. La comunicación que asegura la participación en una inteligencia común es la que asegura disposiciones emocionales e intelectuales semejantes, como modos de responder a las expectaciones y a las exigencias (DEWEY, 1995, p. 16).

Así, el valor social de la educación queda vinculado al carácter educativo de la comunicación en cuanto posibilita la continuidad y renovación de las experiencias vitales 
de la sociedad; y, al mismo tiempo, el desarrollo de cada sujeto en ese entorno en el que será necesaria su participación.

La educación sistematizada se vuelve fundamental para transmitir los recursos y las adquisiciones de sociedades, cada vez más, complejas; sin olvidar que esta transmisión cumple con su tarea en la medida que afirme su valor ético-político. Esto es, guiar la formación, de cada sujeto, para que pueda colaborar con otros en la renovación sostenida de sociedades comprometidas con la tarea de generar experiencias de carácter emancipatorio, que hagan crecer la democracia.

\section{Apuntando a una conclusión: el llamado de la democracia a la educación}

A partir de lo ya expresado, podríamos sostener que Dewey plantea quizás uno de los principales problemas al que se debe enfrentar una teoría filosófico-pedagógica, en referencia a la finalidad social de la educación, la de efectuar una indagación amplia que permita lograr una concepción cada vez más clara del sentido de lo social. Su preocupación deriva de la convicción de que la función social de la educación requiere definir la clase de sociedad que se busca; ya que, las normas y los métodos de la educación varían de acuerdo al ideal de vida social que predomine.

Este es uno de los primeros requisitos que tiene que atender una educación que pretenda ser democrática en los términos deweynianos. Dice, en el texto El hombre y sus problemas:

\footnotetext{
Si no me equivoco, sería de desear que entre los docentes, los padres y las demás personas responsables de la educación, se promoviese justamente esta comprensión inteligente de las fuerzas y de los movimientos sociales de nuestro tiempo y de la función que deben cumplir las instituciones educativas (DEWEY, 1952, p. 67).
}

Todos los conceptos anteriores son centrales para introducirnos en el debate y análisis de aquello que, el autor, llama: “[...] la libertad de la escuela como medio de educación" (DEWEY, 1952, p. 71). Aquí la libertad no es una mera cuestión individual, es sobre todo social; ya que una educación que comprenda su función social y democrática debe impulsar una formación más igualitaria, justa y humana. Podemos pensar que, en el 
marco de una formación liberadora, el método de la inteligencia ${ }^{7}$ (DEWEY, 1952, p. 75), capaz de proponer cambios reales, puede desenvolver la capacidad crítica para comprender los prejuicios, limitaciones y procesos autoritarios y dogmáticos.

Dewey sabe que las escuelas no son los únicos agentes educativos que influyen en la formación humana, y que son ellas también las que reproducen los dogmatismos; sin embargo, sostiene que su tarea es "[...] necesaria para la formación de la inteligencia y las disposiciones que resultan imprescindibles para mantener una auténtica transformación del orden social." (Dewey, 1996, p. 194) Pero, sólo serán capaces de asumir este rol si luchan frente a la limitación de ser reflejo del orden social existente, y logran promover una comprensión positiva de lo que significa la democracia en todas sus aplicaciones concretas.

En un capítulo del libro El hombre y sus problemas, que se titula: El llamado de la democracia a la educación, Dewey señala (con palabras de Horace Mann) que la educación pública “[...] es nuestra única salvación política” (DEWEY, 1952, p. 46), puntualizando que el ejercicio de la auténtica ciudadanía sólo puede formarse en el marco de una educación común, que tenga un claro propósito ético y político. Esta idea refuerza el sentido que tiene la educación en la concepción deweyniana: la de promover y orientar el vínculo entre conocimiento y acción social, para contraponerse a la idea de que la democracia es un patrón fijo de mero funcionamiento de gobierno; y lograr la comprensión necesaria de las fuerzas, movimientos, problemas y necesidades sociales actuales, que requiere la democracia como forma de vivir asociados.

El carácter esencial de la democracia, en tanto forma ética de vida, necesita de la participación de todos en la formación y renovación de valores que regulen la convivencia humana. Por este motivo, Dewey afirma que una democracia genuina debe confiar en el poder de la experiencia compartida, ya que sólo de esta manera, es posible generar progresivamente el conocimiento y los saberes necesarios para guiar la actividad colectiva que representa vivir democráticamente.

\footnotetext{
7 Cuando Dewey habla de método no se refiere a una mera cuestión de procedimiento educativo, hace referencia al accionar, en un sentido amplio, que se posiciona según una orientación social que reclama la comprensión reflexiva de las condiciones sociales; desde la que se definen todos los aspectos que integran el proceso de educación. Por ello, la inteligencia, supone para Dewey, el modo en que se puede asumir un cambio social de carácter radical. Así, frente a fuerzas dogmáticas, autoritarias y violentas, es necesario fomentar una inteligencia dotada de capacidad crítica, para poner frenos a estas fuerzas.
} 
En este sentido la democracia hace un llamado a la educación vista como un ámbito, especialmente, propicio para la reconstrucción o reorganización de la experiencia, acentuando el valor de promover y guiar esta experiencia compartida ${ }^{8}$, que se define por el énfasis que se da a lo social y a la comunidad como categorías claves. En el contexto de este planteo, el principal objetivo de la educación es emancipar y ampliar la experiencia, para lo cual es fundamental llevar a cabo un proceso de observación; análisis e indagación que permita regular su curso.

No obstante saber de la fragilidad de la educación, Dewey refuerza el valor transformador que la caracteriza; y por esta razón, afirma que la educación no puede ignorar, ni delegar la tarea que le reclama la democracia. Este pedido exige un compromiso mayor con el trabajo teórico y práctico que demanda definir lo que se entiende por experiencias educativas y democráticas, en cada contexto. Efectivamente, la educación tiene que asumir un rol dinámico ante la necesidad de una indagación o praxis reflexiva amplia y profunda, que permita formular y problematizar el significado de lo social, en cada etapa que atraviesa la sociedad.

Lo primordial es comprender que esta tarea será siempre una demanda constante, y que cada tiempo con sus ideas, instituciones y costumbres propias deberán problematizar y reformular el significado de lo social; y, por consiguiente, de democracia y de educación. Como destaca muy bien Bernstein, el profundo sentido práctico de la perspectiva deweyniana nos impulsa a hacer un intento serio, para implicar a todos los ciudadanos en la deliberación y el debate público sobre lo que implica vivir democráticamente; para lo cual, también, es necesario que podamos realizarlo mediados por disposiciones que implican comprensión, sensibilidad, creatividad, respeto mutuo, capacidad de acción, todos aspectos necesarios de una inteligencia común.

El desafío es que la educación pueda promover conocimientos y experiencias que conlleven al logro de una inteligencia social, obtenida por medio de un esfuerzo colectivo; y no sólo reducida a una capacidad intelectual de pocos. La lucha es para encontrar y

\footnotetext{
${ }^{8}$ En el texto Democracia y educación de Dewey se expresa, claramente, el carácter democrático de las experiencias compartidas al quedar caracterizadas por una interacción libre y un intercambio variado, que impulsa un reajuste continuo para afrontar la diversidad propia de una sociedad compleja. Y, además, porque a partir de ellas se da el reconocimiento de intereses comunes como un factor de control social, en la medida que se fortalecen formas de vida y formas de educación democrática.
} 
sostener juntos experiencias de participación (en la vida social, cultural y política) que puedan enfrentarse a lógicas y fuerzas que priorizan el lucro por encima de condiciones de vida más justas, igualitarias, incluyentes y solidarias.

Podemos cerrar el texto diciendo que el ideal democrático y pedagógico, que presentamos en este trabajo, es uno de los aportes más destacados que el autor hizo desde su filosofía de la educación; el problema de fines y medios que subyace en el vínculo entre democracia y educación, aún tiene validez en el ámbito de nuestras discusiones pedagógicas, sociales y políticas. Su trabajo conceptual y el propósito crítico, que define su noción de lo social, tienen una vigencia destacada; reafirmada por muchos intelectuales que han vuelto sobre sus escritos con el mismo espíritu crítico y reconstructivo que Dewey sostuvo durante toda su vida, ratificando que el problema sigue siendo el precario destino de la democracia y la necesidad de no verlo nunca como una cuestión resuelta. Más bien como una vivencia cotidiana, que reclama sabiduría práctica para la creación de experiencias más libres y humanas, como ya dijimos, en las que todas y todos participemos y contribuyamos.

\section{Referencias}

BERNSTEIN, R. Filosofía y democracia: John Dewey. Barcelona: Herder, 2010.

DEWEY, J. Democracia y educación. Madrid: Morata, 1995.

DEWEY, J. El hombre y sus problemas. Buenos Aires: Paidos, 1952.

DEWEY, J. La inteligencia y la conducta. Madrid: Ediciones de La Lectura, 1930.

DEWEY, J. La reconstrucción de la filosofía. Buenos Aires: Aguilar, 1959.

DEWEY, J.Liberalismo y acción social. Valencia: Alfons el Magnànim, 1996.

DEWEY, J. Libertad y cultura. Rosario: Rosario, 1946. 